\title{
Characteristics and outcomes of treatment in status asthmaticus patients at emergency department
}

\author{
Kumpol Amnuaypattanapon, Chitlada Limjindaporn, Winchana Srivilaithon, Ittabud Dasanadeba
}

\begin{abstract}
Introduction: The characteristics and treatment outcomes of status asthmaticus patients in emergency department (ED) have not been described previously especially in Thailand.
\end{abstract}

Objective: To describe the characteristics, treatment outcomes and factors associated with status asthmaticus in Thai patients presenting to a single center ED.

Methods: A prospective observational study was performed at Thammasat University hospital, Thailand. The data collected included demographics, asthma history and control, previous ED attendances and hospital admissions, presenting clinical, laboratory and radiographic features, treatments given, and outcomes. Multivariable regression was used to determine independent factors associated with status asthmaticus.

Results: Over one year (2015-16), 209 patients were recruited, aged 6 - 54 years (median 33 y), of whom 145 (69.3\%) had status asthmaticus. The factors associated with status asthmaticus were: (i) age $>60 \mathrm{y}$, (ii) presence of a comorbidity, (iii) having uncontrolled asthma, (iv) hospitalizations or visits to the ED in the last year, and (v) using $>1$ metered dose inhaler canister per month.

Status asthmaticus patients were significantly less likely to speak in sentences $(\mathrm{p}=0.001)$ and more likely to have poor air entry and chest wall retraction $(\mathrm{p}<0.0001)$, an abnormal chest $\mathrm{X}$ ray $(\mathrm{p}=0.011)$, receive magnesium sulphate and be admitted into hospital $(\mathrm{p}<0.0001)$. No patients died.

Conclusions: Status asthmaticus was common in this cohort of patients in our setting. Our findings are consistent with previous studies and underscore the need for better patient management.

Keywords: Acute asthmatic attack, Asthma exacerbation, Emergency department, Status asthmaticus, Severe asthma

\section{From:}

Department of Emergency Medicine, Faculty of Medicine, Thammasat University (Rangsit Campus), Pathum Thani, Thailand

\author{
* Corresponding author: \\ Kumpol Amnuaypattanapon \\ Department of Emergency Medicine, Faculty of Medicine, 99 Moo 18, \\ Phahonyothin Road, Khlong Nueng, Khlong Luang, Pathum thani, \\ Thailand, 12121 \\ E-mail: kump29@gmail.com
}

\section{Introduction}

Asthma exacerbation is one of the most common respiratory illnesses seen in the Emergency Department (ED). ${ }^{1}$ Globally, approximately 360 million people suffer from asthma and some 397,000 people die from asthma every year. ${ }^{2}$ In Thailand, two studies conducted in Bangkok and Khon Kaen showed that the prevalence of wheezing in school-age children ranged from $10-13 \%,{ }^{3,4}$ and adult asthma was $4.6-9.4 \% .{ }^{5}$ Of these asthma patients, 36\% had experienced an acute exacerbation, 35\% had sought treatment in the $\mathrm{ED}$, and $17 \%$ were hospitalized. ${ }^{6}$

Many asthma guidelines such as The Global Initiative for
Asthma guidelines (GINA) and the Thai Asthma Guidelines recommend inhaled beta-agonist therapy, systemic steroids, and oxygen therapy as the initial treatment of acute asthma exacerbation, depending on its severity. ${ }^{7}$ However, some patients do not response within an hour of inhaled bronchodilators and this defines them as having status asthmaticus ${ }^{8,9}$ which needs more intensive treatment and observation and, in some cases, hospital admission. ${ }^{10,11}$

Status asthmaticus patients who need close observation at $\mathrm{ED}$ is the one of cause of ED overcrowding, including in our 
setting in Thailand. Studies evaluating the effects of ED crowding result in reduced quality of care, increased medical error, and increased mortality. ${ }^{12-14}$ Therefore, having a better understanding of status asthmaticus and tis risk factors could reduce ED attendance and overcrowding.

Asthma exacerbation has been well descried in observational studies and its associated factors include a recent history of an antecedent acute exacerbation, ${ }^{15}$ an ED visit or hospitalization in the previous year ${ }^{16,17}$ uncontrolled asthma, ${ }^{15,17-19}$ insufficient use of inhaled or oral corticosteroids, ${ }^{19}$ and a history of a precipitating upper respiratory infection (URTI). ${ }^{18,19}$

There are few data on the outcomes of the initial management of acute asthma exacerbation in the ED in Thailand. Herein, we report the results of a study of asthma exacerbation in a Thai ED.

\section{Methods \\ Study site and participants}

This study was a prospective observational study conducted at the ED of Thammasat University Hospital (TUH), Thailand, from March 2015 to February 2016. All patients with a previous diagnosis of asthma in their medical record who presented with acute exacerbation were considered for inclusion. An exacerbations of asthma was defined by an episode of increased symptoms of shortness of breath, cough, wheezing or chest tightness and deteriorations in lung function from patient's usual status that require a change in treatment. ${ }^{7}$ (2) All patients were enrolled into the study after being informed and having given their written consent. The exclusion criteria were out-of-hospital cardiac arrest due to asthmatic attack, and a diagnosis of COPD. According to the previous literatures, patients who do not respond within an hour of inhaled bronchodilators were defined as status asthmaticus. The study was approved by the committee on Human rights related to research involving human subjects, Faculty of Medicine, Thammasat University.

\section{Clinical management and data collection}

Data were collected on a standard case record form (CRF) which included demographic data, comorbidities, current and previous treatment for asthma. The asthma control status was defined and graded by the GINA assessment guidelines, which consist of 4 questions: in the past 4 weeks, has patient had (1) Daytime asthma symptoms more than twice/week? (2) Any night waking due to asthma? (3) Reliever needed for symptoms more than twice/week? (4) Any activity limitation due to asthma? If none of these: well-controlled, 1-2: partly-controlled, and 3-4: uncontrolled. ${ }^{7}$ The vital signs, clinical presentation and initial laboratory investigations of all patients were recorded. In addition, peak expiratory flow rate (PEFR) which was measured by peak flow meter was applied to patients who are able to use the device.

All treatments were given followed a standard TUH protocol and depended on the severity of asthma: mental status, pulse rate, respiratory rate, accessory muscle use, oxygen saturation, as judged by responsible emergency medicine residents. After 1 hour of treatment, all patients were reviewed and those who did not respond were defined as having status asthmatics. ${ }^{8,9}$

\section{Sample size and data analysis}

The sample size was based on previous retrospective study at TUH that showed that the $24 \%$ of acute asthma exacerbation patients remained in the ED $>4$ hours. ${ }^{1}$ We used the precision method. Estimating a status asthmaticus rate of $25 \%$, a precision of 7.5, we would need to recruit at least 129 patients.

Data were analyzed using descriptive statistics (proportion, mean, standard deviation, median, range). Proportional data were compared using Chi-squared or the Fisher exact test, as appropriate. Continuous variables between groups were analyzed using Wilcoxon Rank sum (skewed data) or unpaired student $t$ (normally distributed data) tests.

We used a generalized linear model to determine risk factors associated with status asthmaticus, entering independent variables with a univariate association of $\mathrm{p}<0.1$. Data were analyzed by STATA software version 14 (Stata Corporation, Texas, USA). A p-value of $<0.05$ was considered to be statistically significant in multivariable analysis.

\section{Results}

A total of 209 patients with asthma exacerbation were included in this study. Of which the median age was 29 years, range 7 to 50, and females slightly outnumbered males. According the previously mentioned criteria, 145 (69.3\%) patients were classified with status asthmaticus. Baseline characteristic of patients with acute asthma exacerbation and status asthmaticus are shown in the Table 1. As shown, patients with status asthmaticus had more severe asthma symptoms before ED visit, more hospitalization and ED visit, and more patients needing MDI reliever $>1$ canister per month than those with non- status asthmaticus.

Comparing the status asthmaticus group to the non- status asthmaticus group by univariate analysis, the following parameters were significantly greater in the status asthmaticus group: (i) age $<6$ and $>60 \mathrm{y}$, (ii) comorbid illnesses, (iii) having partly or uncontrolled asthma, (iv) hospitalizations and visits to the ED in the last year, (v) using $>1$ metered dose inhaler (MDI) canister per month, (vi) history of a recent URTI, but (vii) were significantly less likely to be using asthma controller (e.g. inhaled $\beta$ agonist/steroid).

There were overlapping clinical features between the two groups, notably a history of fever, median respiratory rate, and mean pulse rates and oxygen saturations but the latter two were significantly higher and lower, respectively, in the status asthmaticus group (Table 2). Other significantly different clinical features were the inability to complete full sentences, chest wall retraction, poor air entry on auscultation, having a chest X ray (CXR) performed and having an abnormal CXR.

The non- status asthmaticus group had significantly lower: (i) number of nebulizer treatments, (ii) time to receiving steroids, and (iii) time spent in the ED. None needed magnesium sulphate and none was admitted to hospital.

The multivariable analysis (Table 3) demonstrated fewer significant associations with status asthmaticus and were age $>$ $60 \mathrm{y}$, the presence of a comorbid illness, uncontrolled asthma, an ED visit within the previous year, and using $>1 \mathrm{MDI} / \mathrm{month}$. The only protective factor for status asthmaticus was being on an asthma controlling treatment. 
Table 1. Baseline characteristics of acute asthma exacerbation presented at emergency department.

\begin{tabular}{|c|c|c|c|}
\hline \multirow{2}{*}{ Characteristic } & \multicolumn{2}{|c|}{ Number (\%) } & \multirow{2}{*}{ p-value } \\
\hline & $\begin{array}{c}\text { Status asthmaticus } \\
\quad(n=145)\end{array}$ & $\begin{array}{l}\text { Non-status asthmaticus } \\
\qquad(\mathrm{n}=64)\end{array}$ & \\
\hline Female gender & $86(59.3)$ & $37(57.8)$ & 0.839 \\
\hline Age, year ${ }^{\dagger}$ & $33(6,54)$ & $30(17,43)$ & 0.386 \\
\hline \multicolumn{4}{|l|}{ Age group, year } \\
\hline$<6$ & $35(24.1)$ & $10(15.6)$ & \multirow{4}{*}{0.004} \\
\hline 6 to 15 & $14(9.7)$ & $4(6.3)$ & \\
\hline 16 to 60 & $69(47.6)$ & $47(73.4)$ & \\
\hline$>60$ & $27(18.6)$ & $3(4.7)$ & \\
\hline Comorbid conditions ${ }^{\ddagger}$ & $33(22.8)$ & $3(4.7)$ & $<0.0001$ \\
\hline Family history of asthma & $46(31.7)$ & $12(18.8)$ & 0.054 \\
\hline History of allergy & $57(39.3)$ & $18(28.1)$ & 0.120 \\
\hline Allergic rhinitis & $49(33.8)$ & $15(23.4)$ & \\
\hline Food & $5(3.4)$ & $3(4.7)$ & \\
\hline Drug & $1(0.7)$ & 0 & \\
\hline Other & $2(1.4)$ & 0 & \\
\hline Using asthma controller & 64(44.1) & $41(64.1)$ & 0.008 \\
\hline \multicolumn{4}{|l|}{ Asthma symptom control before ED visit } \\
\hline Well controlled & $15(10.3)$ & $40(62.5)$ & \multirow{3}{*}{$<0.0001$} \\
\hline Partly controlled & $99(68.3)$ & $21(32.8)$ & \\
\hline Uncontrolled & $31(21.4)$ & $3(4.7)$ & \\
\hline Hospitalization for asthma in past year & $45(31.0)$ & $2(3.1)$ & $<0.0001$ \\
\hline ED visit for asthma in past year & $138(95.2)$ & $25(39.1)$ & $<0.0001$ \\
\hline Intubation for asthma in the past & $6(4.1)$ & 0 & 0.099 \\
\hline Recent use of oral corticosteroid & $10(6.9)$ & $1(1.6)$ & 0.111 \\
\hline MDI reliever $>1$ canister/month & $44(30.3)$ & $2(3.1)$ & $<0.0001$ \\
\hline Pre-hospital nebulization & $110(90.2)$ & $44(83.0)$ & 0.181 \\
\hline Precipitating with respiratory infection & $132(91.0)$ & $36(56.3)$ & $<0.0001$ \\
\hline \multicolumn{4}{|l|}{ ED shift } \\
\hline Day & $49(33.8)$ & $27(42.2)$ & \multirow{3}{*}{0.441} \\
\hline Afternoon & $52(35.9)$ & $22(34.4)$ & \\
\hline Night & $44(30.3)$ & $15(23.4)$ & \\
\hline
\end{tabular}

$\dagger$ median(interquartile ranges), ED emergency department, MDI meter dose inhaler ¥Comorbid conditions included: hypertension, diabetes mellitus, and dyslipidemia

Table 2. Clinical presentation, treatment and outcomes of treatment of acute asthma exacerbation patients.

\begin{tabular}{|c|c|c|c|}
\hline \multirow[b]{2}{*}{ Clinical presentation and outcomes } & \multicolumn{2}{|c|}{ Asthma acute exacerbation n(\%) } & \multirow[b]{2}{*}{ p-value } \\
\hline & $\begin{array}{l}\text { Status asthmaticus } \\
\qquad(\mathrm{n}=145)\end{array}$ & $\begin{array}{l}\text { Non-status asthmaticus } \\
\qquad(\mathrm{n}=64)\end{array}$ & \\
\hline Fever & $127(87.6)$ & $59(92.2)$ & 0.959 \\
\hline Heart rate, beat $/ \min ^{\dagger}$ & $119.2(25.9)$ & $107.5(22.7)$ & 0.002 \\
\hline Respiratory rate/min $\mathrm{m}^{*}$ & $29.9(24-32)$ & $28.4(23-28)$ & 0.461 \\
\hline Initial $\mathrm{O}_{2}$ saturation, $\%^{\dagger}$ & $94.6(4.7)$ & $96.8(2.6)$ & 0.001 \\
\hline Initial predicted $\mathrm{PEF}, \%^{\dagger}$ & $46.9(12.3)$ & $57.2(24.7)$ & 0.359 \\
\hline Agitation & $4(2.8)$ & 0 & 0.180 \\
\hline
\end{tabular}


Table 2. (Continues)

\begin{tabular}{|c|c|c|c|}
\hline \multirow[b]{2}{*}{ Clinical presentation and outcomes } & \multicolumn{2}{|c|}{ Asthma acute exacerbation $\mathbf{n}(\%)$} & \multirow[b]{2}{*}{ p-value } \\
\hline & $\begin{array}{c}\text { Status asthmaticus } \\
(\mathrm{n}=145)\end{array}$ & $\begin{array}{c}\text { Non-status asthmaticus } \\
(\mathrm{n}=64)\end{array}$ & \\
\hline \multicolumn{4}{|l|}{ Talk } \\
\hline Sentence & $112(77.2)$ & 63(98.4) & \multirow{3}{*}{0.001} \\
\hline Phrase & $32(22.1)$ & $1(1.6)$ & \\
\hline Word & $1(0.7)$ & 0 & \\
\hline Retraction & $110(75.9)$ & $16(25.0)$ & $<0.0001$ \\
\hline \multicolumn{4}{|l|}{ Wheezing } \\
\hline Expiratory wheezing & $7(4.8)$ & $23(35.9)$ & \multirow{3}{*}{$<0.0001$} \\
\hline Inspiratory/expiratory wheezing & $102(70.3)$ & $37(57.8)$ & \\
\hline Poor air entry & $36(24.8)$ & $4(6.3)$ & \\
\hline Cyanosis & $2(1.4)$ & 0 & 0.345 \\
\hline Time to start bronchodilator, minute ${ }^{*}$ & $8.7(7.31-10.0)$ & $11.2(7.00-15.47)$ & 0.146 \\
\hline Bronchodilator nebulization in ED, No. ${ }^{\dagger}$ & $8.7(7.5-9.9)$ & $1.9(1.0-3.0)$ & $<0.0001$ \\
\hline Steroid treatment at ED & $107(73.8)$ & $45(70.3)$ & 0.603 \\
\hline Time to steroid, minute ${ }^{\ddagger}$ & $80.5(20.0-100.0)$ & $39.5(18.0-54.0)$ & 0.005 \\
\hline Magnesium sulphate treatment at ED & $55(37.9)$ & 0 & $<0.0001$ \\
\hline Time to magnesium sulphate, minute ${ }^{\ddagger}$ & $140.5(70.0-160.0)$ & 0 & $\mathrm{n} / \mathrm{a}$ \\
\hline Non-invasive ventilation & $3(2.1)$ & 0 & $<0.0001$ \\
\hline Neutrophil count, \% ${ }^{*}$ & $8.2(4.8-10.8)$ & $7.4(4.2-9.8)$ & 0.282 \\
\hline Basophil count, \% * & $0.8(0.3-0.8)$ & $0.5(0.3-0.6)$ & 0.209 \\
\hline Eosinophil count, \% * & $4.8(1.3-7.5)$ & $5.4(1.4-7.4)$ & 0.515 \\
\hline Chest radiography done & $142(97.9)$ & $40(62.5)$ & $<0.0001$ \\
\hline Abnormal Infiltration at chest radiography & $21.0(14.8)$ & 0 & 0.011 \\
\hline ED LOS, minute ${ }^{\ddagger}$ & $658.6(240.0-780.0)$ & $150.3(115.0-180.0)$ & $<0.0001$ \\
\hline Admit & $55(37.9)$ & 0 & $<0.0001$ \\
\hline Refer to another hospital & $18(12.4)$ & 0 & $<0.0001$ \\
\hline In-hospital mortality & 0 & 0 & $\mathrm{n} / \mathrm{a}$ \\
\hline Revisit in 48 hours & $1(0.7)$ & $3(3.1)$ & 0.172 \\
\hline Revisit in 1 week & $4(2.76)$ & $1(1.6)$ & 0.602 \\
\hline
\end{tabular}

$\dagger$ mean(SD), ¥median (interquartile ranges), ${ }^{\circ} \mathrm{C}$ degrees Celsius, PEF peak expiratory flow, No. number, n/a not available, ED emergency department, LOS length of hospital stay

Table 3. Factors associated with status asthmaticus in Thai patients presenting to the Emergency Department.

\begin{tabular}{|c|c|c|c|c|}
\hline \multirow{2}{*}{ Clinical variable } & \multicolumn{2}{|c|}{ Univariable analysis } & \multicolumn{2}{|c|}{ Multivariable analysis } \\
\hline & RR (95\%CI) & p-value & $\mathrm{RR}(95 \% \mathrm{CI})$ & p-value \\
\hline \multicolumn{5}{|c|}{ Age group, year (16 - 60 reference) } \\
\hline Less than 6 & $1.31(1.05-1.62)$ & 0.015 & $1.26(0.97-1.63)$ & 0.088 \\
\hline 6 to 15 & $1.31(0.98-1.75)$ & 0.069 & $1.10(0.87-1.41)$ & 0.422 \\
\hline More than 60 & $1.51(1.25-1.83)$ & $<0.0001$ & $1.22(1.01-1.46)$ & 0.036 \\
\hline Family history of asthma & $1.21(1.01-1.44)$ & 0.033 & $1.01(0.85-1.19)$ & 0.908 \\
\hline Comorbid conditions & $1.42(1.22-1.64)$ & $<0.0001$ & $1.19(1.01-1.41)$ & 0.046 \\
\hline Controller used & $0.78(0.65-0.94)$ & 0.009 & $0.75(0.63-0.88)$ & 0.001 \\
\hline
\end{tabular}


Table 3. (Continues)

\begin{tabular}{|c|c|c|c|c|}
\hline \multirow{2}{*}{ Clinical variable } & \multicolumn{2}{|c|}{ Univariable analysis } & \multicolumn{2}{|c|}{ Multivariable analysis } \\
\hline & RR $(95 \% \mathrm{CI})$ & p-value & $\mathrm{RR}(95 \% \mathrm{CI})$ & p-value \\
\hline $\begin{array}{l}\text { Asthma symptoms control before ED visit } \\
\text { (Well controlled reference) } \\
\text { Partly controlled } \\
\text { Uncontrolled }\end{array}$ & $\begin{array}{l}3.03(1.95-4.69) \\
3.34(2.14-5.21)\end{array}$ & $\begin{array}{l}<0.0001 \\
<0.0001\end{array}$ & $\begin{array}{l}1.21(0.85-1.72) \\
1.57(1.07-2.30)\end{array}$ & $\begin{array}{l}0.280 \\
0.021\end{array}$ \\
\hline Hospitalization for asthma in past year & $1.55(1.35-1.78)$ & $<0.0001$ & $0.94(0.80-1.10)$ & 0.428 \\
\hline ED visit for asthma in past year & $5.56(2.80-11.04)$ & $<0.0001$ & $2.32(1.24-4.37)$ & 0.009 \\
\hline Using > 1 MDI canister/month & $1.54(1.35-1.77)$ & $<0.0001$ & $1.21(1.01-1.45)$ & 0.033 \\
\hline Time to come to ED > 24 hours & $1.33(1.12-1.57)$ & 0.001 & $1.01(0.88-1.15)$ & 0.922 \\
\hline Tachycardia $>100$ beats/min & $1.24(0.99-1.54)$ & 0.056 & $0.87(0.73-1.03)$ & 0.111 \\
\hline Initial $\mathrm{O}_{2}$ saturation $>90 \%$ & $0.69(0.60-0.79)$ & $<0.0001$ & $1.03(0.86-1.24)$ & 0.752 \\
\hline Talking in words and phrases & $1.52(1.34-1.72)$ & $<0.0001$ & $1.06(0.89-1.25)$ & 0.491 \\
\hline Retraction & $2.07(1.60-2.69)$ & $<0.0001$ & $1.28(1.01-1.61)$ & 0.038 \\
\hline $\begin{array}{l}\text { Wheezing } \\
\text { (Expiratory wheezing reference) }\end{array}$ & & & & \\
\hline $\begin{array}{l}\text { Inspiratory/expiratory wheezing } \\
\text { Poor air entry }\end{array}$ & $\begin{array}{l}3.14(1.63-6.06) \\
3.86(1.99-7.44)\end{array}$ & $\begin{array}{c}0.001 \\
<0.0001\end{array}$ & $\begin{array}{l}1.21(0.66-2.25) \\
1.29(0.69-2.42)\end{array}$ & $\begin{array}{l}0.538 \\
0.410\end{array}$ \\
\hline Precipitating URTI & $2.48(1.57-3.91)$ & $<0.0001$ & $1.46(0.99-2.14)$ & 0.054 \\
\hline Time to steroid more than 1 hour & $1.30(1.12-1.52)$ & 0.001 & $1.09(0.95-1.24)$ & 0.235 \\
\hline
\end{tabular}

RR risk ratio, CI confidence interval, ED emergency department, LOS length of hospital stay, MDI meter dose inhaler, URTI upper respiratory tract infection

\section{Discussion}

Acute asthma exacerbation is common and challenging problem for ED visit in a patient with asthma. Status asthmaticus, which is a severe form of asthma exacerbation, usually leads to the development several complications, and prolong hospital stay. However, data on status asthmaticus were limited, and most studies were conducted in children, and in the intensive care setting. The present study reports the characteristics and outcomes of patients with asthma exacerbation and status asthmaticus in an ED in Thailand, a middle income Asian country. In this study, we have shown that more than two thirds of patients with asthma exacerbation at ED had status asthmaticus. However, in a previous article, the incidence of status asthmaticus at the ED was reported to be $20-30 \% .{ }^{20}$ This difference could be explained by the heterogeneity in patients' characteristics among studies.

In our status asthmaticus cohort, the adherence to controller medications was unexpectedly low. This low adherence rate could be a result of patients' factors, for example low socioeconomic status, insufficient understanding of asthma management, misconceptions about asthma, and lack of agreement with treatment prescribed. Moreover, previous report has shown than the providers' factors, for example insufficient knowledge of current recommendations, resistance to changing practice, lack of time and resources also play an important role in the adherence to treatment. ${ }^{21}$

The vital signs at presentation do not only indicate the severity and urgency of patients' condition, but also reflect the chance of developing status asthmaticus.22,23 Our study showed that some initial vital signs (e.g. pulse rate and oxygen saturation) were associated with the development of status asthmaticus, even though, these associations were not significant in multivariable analysis. Therefore, vital signs should be promptly assessed and regularly monitored in all patients with acute asthma exacerbation.

In our study, pre-treatment PEFR was assessed at presentation in only $5 \%$ of the patients. Hence, $17 \%$ of our patients received PEFR measurement at 1 hour after treatment. The PEFR measurement is challenging in the ED, especially when patients are first seen because they may not have sufficient energy to perform the test. Clearly, more needs to be done to encourage physicians to conduct all of the GINA recommendations so that asthma management can be improved. ${ }^{7}$

In the current study, a quarter of patients did not receive steroids as a treatment for asthma exacerbation. In those received steroids, the median time to steroid administration was 80.5 minutes. However, GINA guidelines recommend steroid administration within one hour of arriving in the ED because this is associated with reduced hospitalization rates and length of hospital stay, and increased pulmonary function. ${ }^{24-26}$ Magnesium sulphate $\left(\mathrm{MgSO}_{4}\right)$, an adjunctive therapy, is recommended for patients who do not improve clinically within one hour after receiving first-line treatment. ${ }^{7,26}$ In our study, approximately $40 \%$ of the status asthmaticus group received $\mathrm{MgSO}_{4}$ at a median time of $2 \mathrm{~h} 20$ minutes. None of the non -status asthmaticus group needed $\mathrm{MgSO}_{4}$. The percentage of using intravenous $\mathrm{MgSO}_{4}$ in asthma exacerbation at $\mathrm{ED}$ varies among countries such as $7.7 \%$ in Australia and New Zealand, ${ }^{27}$ $2.5 \%$ in North America, ${ }^{28}$ and $93 \%$ in UK. ${ }^{29}$ 
$40 \%$ of our status asthmaticus patients needed hospital admission. This number is lower than what has been reported by Peter et al. ${ }^{9}$ In that study, the admission rate was over $80 \%$, however that was an ICU-based study. In TUH, there is limited access to beds in the general ward and ICU; therefore, patients must be treated over several hours, median of $11 \mathrm{~h}$, in the ED, and this accounts for our relatively low admission rate. Delayed transfer from the ED has been shown to increase all-cause inpatient mortality, length of stay and costs for admitted patients. ${ }^{14}$ Nevertheless, no patients died in our series and a small proportion of patients returned to the ED following an ED discharge at $48 \mathrm{~h}(<1 \%)$ and one week $(<3 \%)$.

The significant factors independently associated with status asthmaticus were advanced age (> $60 \mathrm{y})$, the presence of comorbidities (e.g. hypertension, diabetes mellitus, dyslipidemia), and features of poor asthma control (uncontrolled asthma by history, ED visit in the past year, using > 1 MDI canister/ month). Patients who adhered to their treatment and used their inhalers were protected from status asthmaticus. Our findings agree with previous studies done in pediatric status asthmaticus patients by Chiang et al. ${ }^{18}$ and Carroll et al. ${ }^{11}$ They found that poor disease control and an URIT were factors associated with hospital admission.

Even though, there were several limitations in the present study. Firstly, this was a single-center study, hence the results might not be generally applied to all patients with asthma exacerbation. Secondly, the data was collected only at the ED. Therefore, the clinical information after ED disposition was not included. Our prospective cohort study was the first report of status asthmaticus in ED of Thailand and provided useful information for improving the asthma management.

To date, there was limited data on the impact of asthma treatment on the economy in Thailand. A previous study in Thailand reported the cost of asthma treatment was approximate $\$ 200$ per admission per case. ${ }^{30}$ However, it was notified that this figure was actually lower than the real expense. ${ }^{30}$ Therefore, the treatment strategy aiming at the prevention of acute exacerbation should be generally emphasized.

Our study provided several important issues for improving the asthma management in Thailand. More patients' education should be implemented, including more thorough training on MDI techniques, and emphasizing the need to regularly use inhalers, which have been proven to prevent asthma exacerbations. Hence, they reduce asthma symptoms, improve lung function and quality of life, and reduce asthma-associated mortality. ${ }^{31-33}$

\section{Conclusions}

The current prospective study in acute asthma exacerbation patients has reconfirmed the factors associated with status asthmaticus. Hence, more research is needed to understand cultural and patient centered factors in our setting in order to optimize asthma management using a holistic approach.

\section{Acknowledgements}

All authors have no conflict of interest. This study was financial supported by Faculty of Medicine, Thammasat
University's research fund. KA designed the study, data collection, performed the statistical analysis, interpretation the results, wrote the manuscript. JL, WS, and ID contributed to data collection. All authors read and approved the final manuscripts.

\section{References}

1. Imsuwan I. Characteristics of unscheduled emergency department return visit patients within 48 hours in Thammasat University Hospital. J Med Assoc Thai. 2011;94 Suppl 7:S73-80.

2. GBD 2015 Chronic Respiratory Disease Collaborators. Global, regional, and national deaths, prevalence, disability-adjusted life years, and years lived with disability for chronic obstructive pulmonary disease and asthma, 1990-2015: a systematic analysis for the Global Burden of Disease Study 2015. Lancet Respir Med. 2017;5:691-706.

3. Vichyanond P, Jirapongsananuruk O, Visitsuntorn N, Tuchinda $M$ Prevalence of asthma, rhinitis and eczema in children from the Bangkok area using the ISAAC (International Study for Asthma and Allergy in Children) questionnaires. J Med Assoc Thai. 1998;81:175-84.

4. Teeratakulpisarn J, Pairojkul S, Heng S. Survey of the prevalence of asthma, allergic rhinitis and eczema in schoolchildren from Khon Kaen, Northeast Thailand. an ISAAC study. International Study of Asthma and Allergies in Childhood. Asian Pac J Allergy Immunol. 2000;18:187-94.

5. Dejsomritrutai W, Nana A, Chierakul N, Tscheikuna J, Sompradeekul S, Ruttanaumpawan P, et al. Prevalence of bronchial hyperresponsiveness and asthma in the adult population in Thailand. Chest. 2006;129:602-9.

6. Boonsawat W, Thompson PJ, Zaeoui U, Samosorn C, Acar G, Faruqi R, et al. Survey of asthma management in Thailand - the asthma insight and management study. Asian Pac J Allergy Immunol. 2015;33:14-20.

7. Global Initiative for Asthma. Global strategy for asthma management and prevention 2017 [Internet]. Bethesda: Global Initiative for Asthma; c2016 [cited 2017 Oct 29].

Available from: http://ginasthma.org/2017-gina-report-global-strategy-for -asthma-management-and-prevention/.html.

8. Werner HA. Status asthmaticus in children: a review. Chest. 2001;119: 1913-29.

9. Peters JI, Stupka JE, Singh H, Rossrucker J, Angel LF, Melo J, et al. Status asthmaticus in the medical intensive care unit: A 30-year experience. Respir Med. 2012;106:344-8.

10. Khawaja A, Shahzad H, Kazmi M, Zubairi AB. Clinical course and outcome of acute severe asthma (status asthmaticus) in adults. J Pak Med Assoc. 2014;64:1292-6.

11. Carroll CL, Sala KA. Pediatric status asthmaticus. Critic Care Clin. 2013; 29: $153-66$

12. Weissman JS, Rothschild JM, Bendavid E, Sprivulis P, Cook EF, Evans RS, et al. Hospital workload and adverse events. Med Care. 2007;45:448-55.

13. Kulstad EB, Sikka R, Sweis RT, Kelley KM, Rzechula KH. ED overcrowding is associated with an increased frequency of medication errors. Am J Emerg Med. 2010; 28:304-9.

14. Sun BC, Hsia RY, Weiss RE, Zingmond D, Liang LJ, Han W, et al. Effect of emergency department crowding on outcomes of admitted patients. Ann Emerg Med. 2013;61:605-11. e6.

15. Miller MK, Lee JH, Miller DP, Wenzel SE. Recent asthma exacerbations: a key predictor of future exacerbations. Respir Med. 2007;101:481-9.

16. Suruki RY, Daugherty JB, Boudiaf N, Albers FC. The frequency of asthma exacerbations and healthcare utilization in patients with asthma from the UK and USA. BMC Pulm Med. 2017;17:74.

17. Schatz M, Meckley LM, Kim M, Stockwell BT, Castro M. Asthma exacerbation rates in adults are unchanged over a 5-year period despite high-intensity therapy. J Allergy Clin Immunol Pract. 2014;2:570-4. e1.

18. Chiang BL, Hsieh CT, Wang LC, Lee JH, Yu HH, Lin YT, et al. Clinical course and outcome of children with status asthmaticus treated in a pediatric intensive care unit: a 15-year review. J Microbiol Immunol Infect. 2009;42:488-93.

19. Shah R, Saltoun CA. Chapter 14: Acute severe asthma (status asthmaticus). Allergy Asthma Proc. 2012;33 Suppl 1:S47-50.

20. Rodrigo GJ, Rodrigo C, Hall JB. Acute Asthma in Adults: A Review. Chest. 2004;125:1081-102.

21. Al-Zahrani JM, Ahmad A, Al-Harbi A, Khan AM, Al-Bader B, Baharoon $\mathrm{S}$, et al. Factors associated with poor asthma control in the outpatient clinic setting. Ann Thor Med. 2015;10:100-4. 
22. Atta JA, Nunes MP, Fonseca-Guedes CH, Avena LA, Borgiani MT, Fiorenza $\mathrm{RF}$, et al. Patient and physician evaluation of the severity of acute asthma exacerbations. Braz J Med Biol Res. 2004;37:1321-30.

23. Geelhoed GC, Landau LI, Le Souef PN. Evaluation of $\mathrm{SaO} 2$ as a predictor of outcome in 280 children presenting with acute asthma. Ann Emerg Med. 1994;23:1236-41.

24. Rowe BH, Spooner $\mathrm{CH}$, Ducharme FM, Bretzlaff JA, Bota GW. Corticosteroids for preventing relapse following acute exacerbations of asthma. Cochrane database Syst Rev. 2007;Cd000195.

25. Edmonds ML, Milan SJ, Camargo CA Jr, Pollack CV, Rowe BH. Early use of inhaled corticosteroids in the emergency department treatment of acute asthma. Cochrane Database Syst Rev. 2012;12:Cd002308.

26. Kew KM, Kirtchuk L, Michell CI. Intravenous magnesium sulfate for treating adults with acute asthma in the emergency department. Cochrane Database Syst Rev. 2014;Cd010909.

27. Babl FE, Sheriff N, Borland M, Acworth J, Neutze J, Krieser D, et al. Paediatric acute asthma management in Australia and New Zealand: practice patterns in the context of clinical practice guidelines. Arch Dis Child. 2008;93:307-12.
28. Schuh S, Macias C, Freedman SB, Plint AC, Zorc JJ, Bajaj L, et al. North American practice patterns of intravenous magnesium therapy in severe acute asthma in children. Acad Emerg Med. 2010;17:1189-96.

29. Jones LA, Goodacre S. Magnesium sulphate in the treatment of acute asthma: evaluation of current practice in adult emergency departments. Emerg Med J. 2009;26:783-5.

30 Chuesakoolvanich K. Cost of hospitalizing asthma patients in a regional hospital in Thailand. Respirology. 2007;12:433-8.

31. Juniper EF, Svensson K, O’Byrne PM, Barnes PJ, Bauer CA, Lofdahl CG, et al. Asthma quality of life during 1 year of treatment with budesonide with or without formoterol. Eur Res J. 1999;14:1038-43.

32. Pauwels RA, Lofdahl CG, Postma DS, Tattersfield AE, O'Byrne P, Barnes PJ, et al. Effect of inhaled formoterol and budesonide on exacerbations of asthma. Formoterol and Corticosteroids Establishing Therapy (FACET) International Study Group. N Engl J Med. 1997;337:1405-11.

33. Suissa S, Ernst P, Benayoun S, Baltzan M, Cai B. Low-dose inhaled corticosteroids and the prevention of death from asthma. N Engl J Med. 2000;343:332-6. 